\title{
Bats and Coronaviruses in the Context of COVID-19
}

\author{
Linfa Wang ${ }^{1,2, *} ;$ Matae Ahn'; Danielle E. Anderson ${ }^{1}$
}

In the Chinese zodiac, 2020 was the Year of the Rat. But it was remembered more as a "Year of the Bat" due to the great attention in the general public and scientific community on the role of bats as the reservoir of emerging zoonotic viruses, including severe acute respiratory syndrome coronavirus (SARS-CoV) (1) and the coronavirus disease 2019 (COVID-19) virus, also known as SARS-CoV-2 (2). Here we provide a summary of our current knowledge on the relationship between bats and viruses, particularly coronaviruses, and discuss the various hypotheses for the origin of the COVID-19 virus.

\section{EMERGING ZOONOTIC VIRUSES OF BAT ORIGIN}

In the last 2-3 decades, the world has experienced 6 major viral disease outbreaks caused by emerging zoonotic viruses of bat origin. These include Hendra virus in Australia in 1994, Nipah virus in Malaysia/Singapore 1998/1999, SARS-CoV in China 2002/2003, Marburg in Africa in 2005, MERS-CoV in the Middle East in 2012, Ebola virus in West Africa in 2013, and COVID-19 virus in 2019 in China (Table 1). In addition, there have been many other "less impactful" emerging viruses of bat origin from Australia (Menangle virus) to Malaysia (Tioman virus and Melaka virus) and Africa (Sosuga virus). For more information on this rapid growing area of research, please refer to reviews and books published recently on this topic (3-4).

\section{BAT IMMUNITY AND ITS SPECIAL STATUS AS VIRUS RESERVOIR}

Bats are unique as the only mammals capable of powered flight. During their 65 million years of adaptive evolution, bats have displayed several unique biological features including long lifespan relative to their body size, decreased susceptibility to cancer, and ability to host various viruses without suffering from clinical diseases. In particular, the asymptomatic viral reservoir status of bats has attracted increasing interest and efforts to study their immune system.

Although research into bat immunity is still at its infancy, significant progress has been made in the last ten years. Bats exhibit a unique balance between enhanced host defense responses and immune tolerance (5-6). Mechanisms of enhanced host defense include constitutive expression of some interferons and/or interferon-stimulated genes, higher expression of heat-shock proteins, and efficient drug efflux via the ATP binding cassette subfamily B member 1 (ABCB1) transporter. On the other hand, dampened stimulator of interferon genes (STING) and inflammasome signaling are key examples of immune tolerance in

TABLE 1. Emerging zoonotic virus outbreaks related to bats. Cumulative infected humans is the sum from all outbreaks.

\begin{tabular}{|c|c|c|c|c|c|c|c|}
\hline Viral Disease & Year & Country (initial) & Infected & Deaths & Cumulative infected (deaths) & Origin & Intermediate host \\
\hline Hendra & 1994 & Australia & 2 (+19 horses) & 1 & $7(5)$ & Bat & Horse \\
\hline Nipah & 1998-1999 & Malaysia & 265 & 105 & $704(412)$ & Bat & Bat*/Pig \\
\hline SARS & $2003-2004$ & China & 8,098 & 774 & $8,098(774)$ & Bat & Civet \\
\hline Marburg & 2005 & Angola & 252 & 227 & $474(380)$ & Bat & Monkey/Bat ${ }^{\dagger}$ \\
\hline Ebola & 2013 & Guinea/West Africa & 28,646 & 11,323 & $34,975(15,253)$ & Bat & Bat/Monkey \\
\hline MERS & 2014 & Saudi Arabia & 255 & 93 & $2,494(858)$ & $\mathrm{Bat}^{\S}$ & Camel \\
\hline COVID-19 & 2019 & China & 99,931 & 4,810 & $98,280,844(2,115,759)^{\pi}$ & Bat* & $X^{* *}$ \\
\hline
\end{tabular}

\footnotetext{
${ }^{*}$ Direct bat to human transmission via urine in palm sap as well as bat to pig, pig to human transmission.

${ }^{\dagger}$ Either macaques (intermediate) or bats (direct) believed to be hosts.

$\S$ Ancestral origin believed to be bat based on close genetic relatedness to bat-borne viruses and evolutionary trajectory.

"Data current on 27 January 2021. https://www.who.int/publications/m/item/weekly-epidemiological-update---27-january-2021.

${ }^{*}$ Currently unknown.
} 
bats. Strikingly, recent studies demonstrate multiple mechanisms of dampened inflammasome activation at different levels of the signaling. These include the loss of PYRIN and HIN domain (PYHIN) gene family including absent in melanoma 2 (AIM2), dampened transcriptional priming and protein function of NLR family pyrin domain containing 3 (NLRP3), and reduced downstream caspase-1 activity and/or IL-1 $\beta$ cleavage, which results in an overall reduction in virusinduced or age-related inflammation (5). A deeper understanding of how bats fine-tune this balance will provide valuable lessons for combating viral diseases, aging, and cancer in humans.

\section{BAT CORONAVIRUSES}

The association of coronaviruses $(\mathrm{CoVs})$ with bats started with the discovery of SARS-related CoVs in bats during the investigation for the origin of SARS$\mathrm{CoV}$ (1). Since then, bats have been identified as a rich source of genetically diverse $\mathrm{CoV}$ s all around the world. Bats are undoubtedly the richest source of $\mathrm{CoVs}$, displaying greater genetic diversity of $\mathrm{CoVs}$ from any other animal hosts ( 7 ).

CoVs contain the largest ssRNA genome $(>30 \mathrm{~kb})$ of all known RNA viruses and are members of the order Nidovirales. It is well documented that replication of large DNA genomes is less error prone due to proofreading capacity of the DNA polymerase. In contrast to DNA polymerase, RNA-dependent RNA polymerases (RdRp) lack replication fidelity. This is believed to be one of the reasons that RNA viral genomes tend to be smaller and viruses such as influenza virus use genome segmentation as a means of increasing genome-coding capacity. This paradigm was revisited after the discovery of a 3'-to-5' exoribonuclease (ExoN). ExoN, a homolog of canonical DNA proof-reading enzymes, which is exclusively encoded by nidoviruses with genomes larger than $20 \mathrm{~kb}$ (8). While the nidovirus-unique ExoN can explain why $\mathrm{CoVs}$ can maintain such a large RNA genome, the special "affinity" of CoVs towards bats remains elusive.

\section{IS THE COVID-19 VIRUS A BAT VIRUS?}

One year after the first detection of COVID-19 infection and more than 100,000 scientific publications on the COVID-19 pandemic, there are still many key questions remaining unanswered. One major question involves the origin of the causative agent of COVID-19. To address this question, it is important to differentiate the following viral terms. 1) Outbreak virus: the virus which was directly responsible for causing the outbreak, such as the first isolate (Wuhan-Hu-1) of COVID-19 virus. 2) Progenitor virus: this refers to a very closely related virus which is not identical to the outbreak virus, but could have evolved into an outbreak virus with minimal mutation(s). 3) Ancestral virus: this is the ancestor of both the progenitor virus and the outbreak virus residing in its natural reservoir host for a long time.

COVID-19 virus is a member of the species SARSrelated coronavirus (SARSr-CoV) which includes SARS-CoV and many other CoVs of bat origin. The species is currently composed of two lineages or clades, one related to SARS-CoV and the other more related to virus causing COVID-19 (2). More than 10 COVID-19-virus related coronavirus genome sequences have been reported and over $80 \%$ of them originated from bats (9), including the RaTG13 sequence which has a genome that identifies $96 \%$ with COVID-19 virus. It is therefore most likely that the ancestral virus is from bats (10). The origin and geographic distribution of the progenitor virus remains elusive. In Table 2, alternative hypotheses of key events related to the origin of COVID-19 virus are summarized.

TABLE 2. Uncertainties surrounding key events relating to the origin and early transmission of COVID-19 virus.

\begin{tabular}{|c|c|c|}
\hline Event & Hypothesis-1 & Hypothesis-2 \\
\hline First human infection time & December 2019 & Months earlier \\
\hline First human infection location & Wuhan & Other site in China or outside China \\
\hline Introduction of virus to Wuhan & By infected animal & By infected human \\
\hline Type of virus introduced to Wuhan & The progenitor virus & The outbreak virus \\
\hline $\begin{array}{l}\text { The role of the Huanan Seafood } \\
\text { Wholesale Market }\end{array}$ & $\begin{array}{l}\text { The site of spillover (i.e., animal to } \\
\text { human transmission) }\end{array}$ & $\begin{array}{l}\text { The site of spillback-then-spillover (i.e. human to animal } \\
\text { transmission, which led to amplification/adaptation in animal } \\
\text { and followed up by animal to human transmission) }\end{array}$ \\
\hline Host of the progenitor virus & Animal & Human \\
\hline
\end{tabular}




\section{CONCLUSION}

Bats are undoubtedly one of the most important mammalian reservoir hosts for emerging viruses. This can most likely be attributed to their unique immunity formed as part of the long-term adaptation to flight. $\mathrm{CoVs}$ seem to have a special co-evolutionary relationship with bats and the ancestral virus of COVID-19 virus also originated from bats. The origin of COVID-19 virus or its progenitor virus and the early transmission event from animal(s) to human remain elusive. The scientific community needs to keep an open mind in searching for the origin of COVID-19 virus as alternative hypotheses have been postulated for each of the key events from sources, timing to geographic locations.

doi: $10.46234 / \mathrm{ccdcw} 2021.045$

\# Corresponding author: Linfa Wang, linfa.wang@duke-nus.edu.sg. \begin{tabular}{l}
\hline Programme in Emerging Infectious Diseases, Duke-NUS Medical \\
School, Singapore; ${ }^{2}$ SingHealth Duke-NUS Global Health Institute, \\
Singapore.
\end{tabular}

Submitted: February 02, 2021; Accepted: February 03, 2021

\section{REFERENCES}

1. Li WD, Shi ZL, Yu M, Ren WZ, Smith C, Epstein JH, et al. Bats are natural reservoirs of SARS-like coronaviruses. Science 2005;310(5748): 676 - 9. https://pubmed.ncbi.nlm.nih.gov/16195424/.

2. Zhou P, Yang XL, Wang XG, Hu B, Zhang L, Zhang W, et al. A pneumonia outbreak associated with a new coronavirus of probable bat origin. Nature 2020;579(7798):270 - 3. https://www.nature.com/ articles/s41586-020-2012-7.

3. Wang LF, Anderson DE. Viruses in bats and potential spillover to animals and humans. Curr Opin Virol 2019;34:79 - 89. https://pubmed. ncbi.nlm.nih.gov/30665189/.

4. Wang LF, Cowled C. Bats and Viruses: A New Frontier of Emerging Infectious Diseases. Hoboken, NJ, USA: Johh Wiley \& Sons, Inc. 2015. https://onlinelibrary.wiley.com/doi/book/10.1002/978111881 8824.

5. Irving AT, Ahn M, Goh G, Anderson DE, Wang LF. Lessons from the host defences of bats, a unique viral reservoir. Nature 2021;589(7842): 363 - 70. https://www.nature.com/articles/s41586-020-03128-0?utm_ source=feedburner\&utm_medium $=$ feed.

6. Banerjee A, Baker ML, Kulcsar K, Misra V, Plowright R, Mossman K. Novel insights into immune systems of bats. Front Immunol 2020;11: 26. https://pubmed.ncbi.nlm.nih.gov/32117225/.

7. Cui J, Li F, Shi ZL. Origin and evolution of pathogenic coronaviruses. Nat Rev Microbiol 2019;17(3):181 - 92. https://pubmed.ncbi.nlm. nih.gov/30531947/.

8. Lauber C, Goeman JJ, del Carmen Parquet M, Nga PT, Snijder EJ, Morita $\mathrm{K}$, et al. The footprint of genome architecture in the largest genome expansion in RNA viruses. PLoS Pathog 2013;9(7): e1003500. https://journals.plos.org/plospathogens/article?id=10.1371/journal.ppat. 1003500.

9. Hul V, Delaune D, Karlsson EA, Hassanin A, Tey PO, Baidaliuk A, et al. A novel SARS-CoV-2 related coronavirus in bats from Cambodia. bioRxiv 2021. http://dx.doi.org/10.1101/2021.01.26.428212.

10. Lytras S, Hughes J, Xia W, Jiang XW, Robertson DL. Exploring the natural origins of SARS-CoV-2. bioRxiv 2021. http://dx.doi.org/10. 1101/2021.01.22.427830.

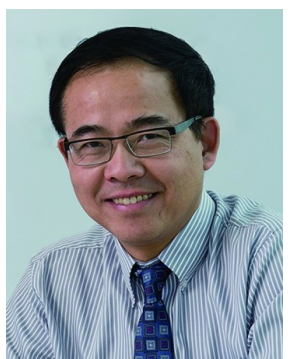

Linfa Wang, PhD

Professor, Programme in Emerging Infectious Diseases, Duke-NUS Medical School 